\title{
BMJ Open Patient-reported confidence in primary healthcare: are there disparities by ethnicity or language?
}

\author{
Sabrina T Wong, ${ }^{1,2,3}$ Charlyn Black, ${ }^{2,4}$ Fred Cutler, ${ }^{5}$ Rebecca Brooke, ${ }^{6}$ \\ Jeannie L Haggerty, ${ }^{7}$ Jean-Frederic Levesque ${ }^{8,9}$
}

To cite: Wong ST, Black C, Cutler $\mathrm{F}$, et al. Patientreported confidence in primary healthcare: are there disparities by ethnicity or language?. BMJ Open 2014;4:e003884.

doi:10.1136/bmjopen-2013003884

- Prepublication history for this paper is available online. To view these files please visit the journal online (http://dx.doi.org/10.1136/ bmjopen-2013-003884).

Received 24 August 2013 Revised 24 December 2013 Accepted 10 January 2014

CrossMark

For numbered affiliations see end of article.

Correspondence to Dr Sabrina T Wong; Sabrina.wong@nursing.ubc.ca

\begin{abstract}
Objective: To examine whether confidence in primary healthcare (PHC) differs among ethnic-linguistic groups and which PHC experiences are associated with confidence.
\end{abstract}

Design: A cross-sectional study where patient surveys were administered using random digit dialling. Regression models identify whether ethnic-linguistic group remains significantly associated with confidence in PHC.

Setting: British Columbia, Canada.

Main outcome measures: Confidence in PHC measured using a 0-10 scale, where a higher score indicates increased confidence in the ability to get needed PHC services.

Participants: Community-dwelling adults in the following ethnic-linguistic groups: English-speaking Chinese, Chinese-speaking Chinese, English-speaking South Asians, Punjabi-speaking South Asians and English-speakers of presumed European descent.

Findings: Based on a sample of 1211 respondents, confidence in PHC differed by ethnicity and the ability to speak English. Most of the differences in confidence by ethnic-linguistic group can be explained by various aspects of care experience. Patient experiences associated with lower confidence in PHC were: if care was received outside Canada, having to wait months to see their regular doctor and rating the quality of healthcare as good or fair/poor. Better patient experiences of their doctor being concerned about their feelings and being respectful and if they found wait times acceptable were associated with higher levels of confidence in PHC. The final regression model explained $30 \%$ of the variance.

Conclusions: Improving the delivery of PHC services through positive interactions between patients and their usual provider and acceptability of wait times are examples of how the PHC system can be strengthened.

\section{INTRODUCTION}

Confidence in healthcare can be defined as a belief in the trustworthiness or reliability of care, and understood as a perception that influences how patients make decisions.

\section{Strengths and limitations of this study}

- Having the survey available in English, Chinese and Punjabi enabled us to collect data from those rarely included in reports about primary healthcare $(\mathrm{PHC})$ experiences together with their confidence in these services.

- These were cross-sectional data collected in one Canadian province; therefore, generalisability to other settings may be limited and only associations between patients' experiences and confidence in PHC can be inferred.

- Asking a question about confidence in a survey is a snapshot of an attitude that is never permanently crystallised, but likely has some stability over time.

Reduced confidence in healthcare on the part of patients is a serious concern because it can lead to poorer health outcomes and increase system costs. ${ }^{1-7}$ It can also lead to avoidance of care or seeking second and third opinions, requesting the newest prescription drug, and unnecessary medical tests. Previous works have shown that patients with higher confidence are more likely to seek care and show greater compliance with treatment. ${ }^{5-12}$ Indeed, it has long been recognised that the public's confidence in medicine's ability to provide care is one of its greatest assets, ${ }^{13}$ allowing practitioners to define the scope of medical work and increase their political and clinical autonomy. Confidence eliminates uncertainty, implies stability and suggests that a system is in place to effectively deal with any risks.

Poor health outcomes or inequities in healthcare that are known to occur among diverse ethnic populations are associated with their confidence in the healthcare system. $^{10} 12{ }^{14-17}$ Previous studies in the USA and the UK have suggested that ethnic and linguistic minorities have lower levels of confidence or trust, which could lead to health disparities. ${ }^{18-20}$ For example, 
African-Americans generally have less confidence in primary healthcare (PHC) providers and the healthcare system; observed differences in trust have been attributed to divergent experiences, ${ }^{15}{ }^{21}$ historical legacies ${ }^{16}$ and lower levels of generalised social trust. ${ }^{18}$ Some sources of confidence are pertinent for one ethnic group but not for others. For example, gender has a stronger relationship with trust among non-Latino whites compared with African-Americans. ${ }^{15}$ Language was a concern for Hispanics who expressed reduced confidence when they had difficulty communicating with the PHC provider due to a language barrier. ${ }^{22}$

There remains a paucity of literature about levels of confidence in healthcare held by ethnic or language groups in other countries, including Canada. The purpose of this study was to examine levels of confidence among ethnic and linguistic minorities. The specific research questions were: (1) Does confidence in PHC differ between ethnic-linguistic groups? and (2) What PHC experiences are associated with confidence?

\section{METHODS}

\section{Design and participants}

This cross-sectional survey was designed to examine patient experiences in PHC across three ethnic and language groups. The survey reflected important dimensions of PHC based on our previous work ${ }^{23}$ and past research, ${ }^{24}{ }^{25}$ sociodemographic characteristics, health status and confidence in the healthcare system. Each participant was given a definition of PHC as the: "Provision of healthcare services outside of hospital settings. Family physicians and nurses most often provide these services. These clinicians assume responsibility for a large part of your personal healthcare needs-they provide services (eg, immunisations) to keep people from getting sick and provide services when people are sick."

The survey, originally developed in English, was translated to Chinese and Punjabi by research assistants (RAs) and then back-translated to English by different RAs. ${ }^{26}$ All RAs were fluent in written and spoken English as well as in Chinese or Punjabi. To ensure semantic equivalence, ${ }^{27-31}$ we first undertook the translation process and then further refined items with cognitive interviews $^{32-34}$ that were completed with a small group of Chinese $(n=10)$ and Punjabi $(n=10)$ participants. Semantic equivalence was satisfied when items originally developed in English had similar meanings to people whose first language is not English. That is, the same expression existed in the target culture and equivalent expressions could be found for idioms and colloquialisms and the technical features of the language were equivalent (eg, complexity, syntax and grammar). In order to ensure operational equivalence (eg, administration using low-literacy terms and correct skip patterns), the survey was pilot tested in a smaller sample of Chinese-speaking $\quad(n=121) \quad$ and Punjabi-speaking $(\mathrm{n}=131)$ participants.
Random digit dialling (RDD) methods were used to collect a random sample of ethnic Chinese, South Asian and English speakers of presumed European descent (herein ESED) participants' reports of PHC experiences. A random sample of telephone numbers ${ }^{35}$ was obtained from British Columbia's (BC's) 28 census divisions, based on relative population. For example, the Greater Vancouver Regional District (GVRD) contained $51 \%$ of BC's population; thus, $51 \%$ of the sample was drawn from the GVRD. In order to increase the probability of contacting individuals whose first language was either Chinese or Punjabi, we used two approaches to randomly selecting telephone numbers. First, we oversampled telephone numbers in census dissemination areas where there was a high likelihood of speaking Chinese or Punjabi at home. Second, we oversampled Chinese and South Asian households where the listed surname for the telephone number matched the list of Chinese or South Asian surnames maintained by ASDE, which maintains the Canada Survey Sampler. ${ }^{35}$

The survey sampler is a general, geographically stratified, telephone population, random sampling programme. It samples by RDD methodology. The samples are checked against published phone lists to divide the RDD into 'directory listed' and 'directory not listed' components. ${ }^{35}$ In an effort to ensure that participants were accessing similar PHC services, we obtained a random selection of telephone numbers for ESED participants from telephone exchanges and geographical areas where at least one completed survey from Chinese-speaking or Punjabi-speaking participants occurred.

\section{Data collection procedures}

Computer-assisted telephone interviews took place in Chinese (Cantonese or Mandarin), Punjabi or English. Using a standard telephone script, one adult per household was randomly selected by asking to speak to the adult with the next birthday. Eligibility criteria included: (1) age 19-90 years, (2) Chinese, Punjabi or English speaking, (3) no cognitive impairments and (4) had visited a family doctor or nurse practitioner in the past 12 months. Verbal consent was obtained and each survey took an average of $27 \mathrm{~min}$ to complete.

\section{Variables of interest}

Drawing on previous work measuring consumer confidence, ${ }^{24} 25$ our dependent variable of interest was patients' reports of their confidence in PHC: "On a scale of $0-10$, where 0 means no confidence at all and 10 means total confidence, how much confidence do you have in the ability to get the primary health care services you need?"

We examined which patient-reported PHC experiences were associated with confidence. Our analyses were informed by previous works. Increased trust (a closely related concept) is associated with: positive interpersonal style of physician, ${ }^{7213031}$ increased time spent with the physician, continuity of care ${ }^{153233}$ and coordination of 
care ${ }^{36}$ We measured six dimensions of PHC: accessibility, utilisation, relationship continuity of care, interpersonal communication, quality and acceptability of care and care obtained outside Canada (table 1). Accessibility was measured by patients' reports of having a usual source of care, length of wait time to see a provider and unmet healthcare needs. ${ }^{37}$ Utilisation was measured by the respondent's report of the number of times he/she had visited their doctor for either a physical or mental health issue. Relationship continuity was measured by the patient's self-report of the length of time he/she had been with the same provider. Interpersonal processes of care was measured using the Interpersonal Processes of Care (IPC) short form which is a publicly available reliable and valid instrument. ${ }^{38}$ IPC items (table 1) were combined to create scale scores for: unhurried communication, explained results, patient-centered decisionmaking and interpersonal style. All scales were constructed such that a higher score meant more of the concept.

To measure the dimension of quality, participants were asked to provide an overall rating of the quality of healthcare received in the past 12 months. We constructed the acceptability of care from two items where patients reported on the acceptability of wait times for routine and urgent services. One additional measure, receiving care outside of Canada, was also included (see table 1).

\section{Other covariates}

Our analyses included sociodemographic characteristics and health status as potentially confounding variables. These variables included: gender (male and female), age (continuous variable), education (less than high school, high school, some university or completed college, completed undergraduate degree and graduate degree), yearly household income $(<\mathrm{C} \$ 10000-\mathrm{C} \$ 30000$, C $\$ 30001-\mathrm{C} \$ 50000, \quad \mathrm{C} \$ 50001-\mathrm{C} \$ 80000, \quad \mathrm{C} \$ 80001-\mathrm{C}$ $\$ 100000$ and $>\mathrm{C} \$ 100000$ ) and marital (yes or no), employment (full-time or not full-time) and immigrant status (born in Canada and years living in Canada).

Health status variables included: presence of a chronic condition, number of chronic conditions and self-rated health (excellent, very good, good, fair or poor). Participants were asked whether a health professional had ever diagnosed or treated them for heart disease (yes/no), high blood pressure or hypertension (yes/ no), depression (yes/no), arthritis (yes/no), diabetes (yes/no) or some other chronic condition. We constructed a variable that provided information on whether a participant had one, two or three or more chronic conditions. Reports of self-rated health status were collapsed into three categories: excellent/very good, good and fair/poor.

\section{Data analysis}

Prior to undertaking data analysis for this study, we conducted psychometric testing of the items and scales. We examined single-item responses for their distribution. If the items were part of a scale, internal consistency reliability was examined using Cronbach's $\alpha$ coefficient. The four IPC scales and the Acceptability scale met adequate internal consistency reliability criterion of $>0.70 .^{39}$

Descriptive statistics were calculated to characterise five ethnic and linguistic groups: English-speaking Chinese, Chinese-speaking (Mandarin or Cantonese) Chinese, English-speaking South Asians, Punjabi-speaking South Asians and ESED. Although missing data on individual items were low, missing data for scales ranged from $11 \%$ (unmet healthcare needs) to $43 \%$ (household income; see table 4). Multiple imputations using the expectation maximisation algorithm for missing income data were calculated using Stata V.11. However, since patient-centered decision-making may not have been applicable to all participants (true missing data), it was excluded from the regression model because of the high amounts of missing (44.8\%) data.

We conducted a series of stepwise ordinary least squares regression models to identify whether ethnic-linguistic group remained statistically significant after controlling for other variables. Four blocks of variables were entered into the regression models in the following order: (1) ethnic-linguistic group, (2) sociodemographic characteristics, (3) health status and (4) the six dimensions of patient experiences in PHC: accessibility, utilisation, relationship continuity of care, interpersonal processes of care, quality and acceptability of care and obtaining care outside Canada. Of the three items asking about length of waiting time to see their usual provider, we used one variable (length of wait) to keep the model more parsimonious.

In order to answer our research questions, ethnic-linguistic group and patient experiences in PHC were considered as independent variables, whereas sociodemographic characteristics and health status were considered as potentially confounding variables. Statistical tests were two-tailed, reflecting our uncertainty about the likely direction of many of the effects. Descriptive statistics were conducted using SAS V.9.1, and regression modelling was conducted using Stata V.11.

To guide our analytical work, we hypothesised that the following experiences of care would be significantly associated $(p<0.01)$ with higher confidence in PHC

A. Accessibility: patients who have a usual source of care.

B. Interpersonal Processes of Care: patients who scored higher on communication, decision-making and interpersonal style scale.

C. Quality: patients who reported a higher rating of quality of healthcare received in the past 12 months.

D. Acceptability: patients who reported that wait times for routine and urgent care were more acceptable.

\section{RESULTS}

A total of 1211 participants answered our survey. Response rates were calculated based on ethnicity, 
Table 1 Description of independent variables that represent patient experience with primary care

\begin{tabular}{ll}
\hline Dimension & Definition \\
\hline Accessibility & The capacity to obtain PHC services \\
& in a timely fashion
\end{tabular}

Item/scale name and questions

\section{Usual source of care (1 item):}

Is there a doctor or place that you usually go if you are sick or need advice about your health? (yes, no) Unmet healthcare need (2 items):

During the past 12 months was there ever a time when you felt you needed healthcare but you didn't receive it? (yes, no)

Again, thinking about the last 12 months, please tell me if you agree or disagree with this statement: "My regular doctor delivers a range of services, such as routine exams and prevention that meet most of all of my health needs." (Strongly disagree, disagree, agree, strongly agree)

Usual wait at regular place of care (1 item):

How long do you usually have to wait at your regular doctor's office or place of care from the time of your appointment until your visit begins? (0-10 $\mathrm{min}, 10-20 \mathrm{~min}, 20-30 \mathrm{~min}, 30-60 \mathrm{~min}$, more than $60 \mathrm{~min}$ ) Wait for healthcare (3 items):

During the past 12 months, was there ever a time when you got healthcare that you needed but you had to wait? (yes, no)

If yes, how long was the healthcare you needed delayed? Was it a matter of hours, days, weeks or months, or did you never receive it? (Less than a day, days, weeks, months, never received)

How quickly are you able to see your regular doctor when the appointment you need is for routine care? (the same day, the next working day, within three working days, within four working days, after five or more working days)

How quickly have you been able to see your regular doctor or a doctor at your regular place of care when the appointment you need is for an urgent but minor health problem? (the same day, the next working day, within three working days, within four working days, after five or more working days) Number of visits to doctor in past year (2 items):

Turning to your physical health, in the past 12 months, how many times have you seen or talked with your regular doctor or a doctor at your usual place of care about your physical health? (number of visits recorded)

In the past 12 months, how many times have you seen or talked to your doctor about your mental or emotional health (eg, being burnt out or depressed)? (number of visits recorded)

Relationship continuity of Long-term patient-provider care relationship Length of time seeing same doctor (1 item):

How long have you been seeing this same doctor or going to the same place? $(0-3,4-9$ months, 1 year (10-18 months), 2, 3-5, 6 years or more)

Interpersonal Processes Provider effectively communicates of Care ${ }^{38} \quad$ with patient Unhurried communication (2 items combined to create scale):

In the past 12 months how often did your doctor speak too fast?

How often did your doctor use words that were hard to understand? (never, rarely, sometimes, usually, always; scale reversed so higher score is better)

Explained test results (2 items combined to create scale):

How often did doctors explain your test results such as blood tests, X-rays or cancer screening tests?

How often did doctors clearly explain the results of your physical examination? (never, rarely, sometimes, usually, always)

Provider involves the patient in Patient-centered decision making (2 items combined to create scale): 


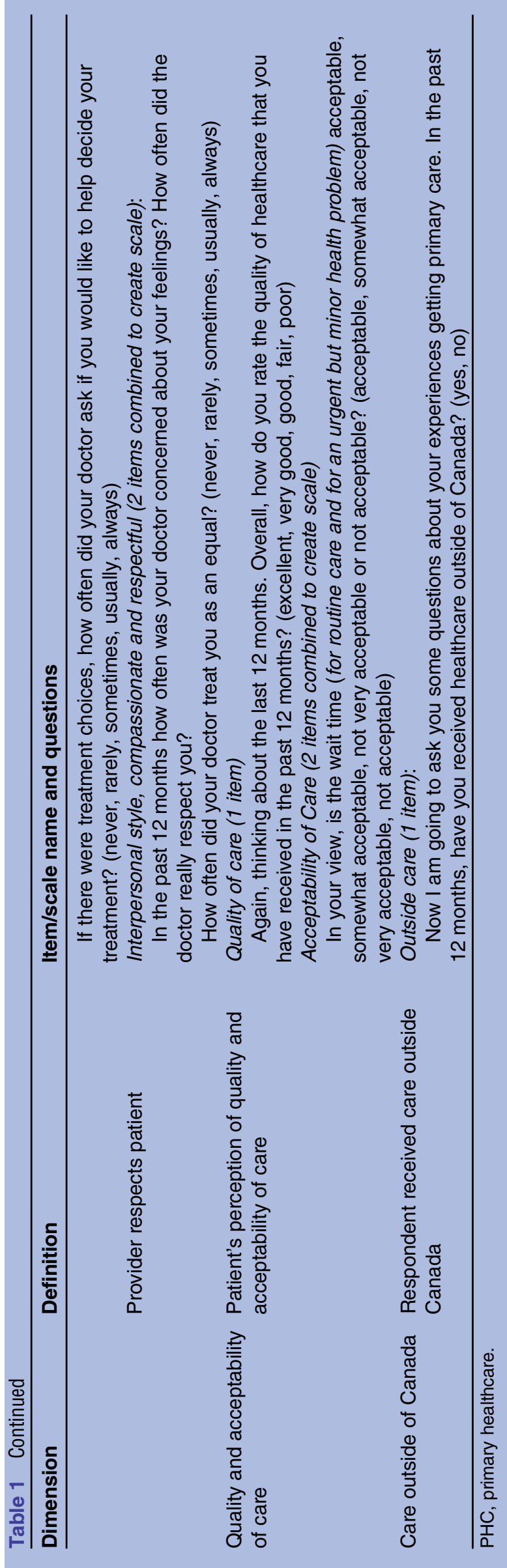

language and the number of complete interviews, divided by the total number of interviews (complete plus partial) plus the number of non-interviews that involve the identification of and contact with an eligible respondent (eg, refusal and break-off).$^{40}$ Telephone numbers were checked to ensure they were operational. Attrition due to telephone numbers not being operational ranged from $17 \%$ (Punjabi) to $30 \%$ (ESED). Next, telephone numbers were called and eligibility of potential participants was assessed. Attrition of participants due to not meeting the eligibility criteria of the study ranged from $7 \%$ (Caucasian) to $20 \%$ (Chinese). The response rates ranged from 25\% (ESED) to $50 \%$ (Chinese-speaking and English-speaking Chinese). Once potential participants responded to the telephone interviewer, the cooperation rate was $79 \%$ (Punjabi-speaking South Asian) to 94\% (Chinese-speaking Chinese).

The characteristics of the total sample and by ethniclinguistic groups are displayed in table 2. There was a significant amount of heterogeneity between the ethniclinguistic groups. Only $31 \%$ of the participants in the total sample were born in Canada, with Chinese-speaking and Punjabi-speaking groups made up mostly of immigrants; approximately half of those who immigrated to Canada did so after 1990. All groups, except Chinese-speaking Chinese, had lived in Canada for over 20 years.

In the total sample, half of the participants reported having at least one chronic condition. Yet, over $60 \%$ of ESED reported having a chronic condition followed by Punjabi-speaking South Asians (54\%), English-speaking South Asians (48\%) and the English and Chinesespeaking Chinese (40\%). For all groups, the most frequently reported chronic condition was hypertension. The presence of depression was reported significantly less by English (6\%) and Chinese-speaking Chinese (4\%) compared with any other group. Almost one-third of ESED and one of every five Punjabi-speaking South Asians reported having two or more chronic conditions. Over one-third of Chinese-speaking and Punjabi-speaking participants reported their health as fair or poor.

\section{Confidence}

Figure 1 shows that participants' mean level of confidence in PHC ranged from 7.98 (ESED) to 6.62 (Chinese-speaking Chinese), on a scale of 1-10. Three ethnic-linguistic groups, Chinese-speaking $(p<0.001)$ and Punjabi-speaking $(\mathrm{p}<0.001)$ and English-speaking South Asians $(p<0.05)$, reported significantly lower confidence in PHC compared with other English speakers. Given that the majority of Chinese-speaking Chinese and Punjabi-speaking South Asians were not born in Canada, figure 1 also suggests that these groups have significantly lower confidence in PHC compared with their ESED counterparts. 


\begin{tabular}{|c|c|c|c|c|c|c|c|}
\hline & $\begin{array}{l}\text { Chinese- } \\
\text { English }(n=142)\end{array}$ & $\begin{array}{l}\text { Chinese- } \\
\text { Chinese }(n=284)\end{array}$ & $\begin{array}{l}\text { South Asian } \\
\text { English }(n=164)\end{array}$ & $\begin{array}{l}\text { South Asian } \\
\text { Punjabi }(n=307)\end{array}$ & $\begin{array}{l}\text { English speakers } \\
\text { of presumed European } \\
\text { descent }\left(n=314^{\star}\right)\end{array}$ & $\begin{array}{l}p \text { Value for } \\
\chi^{2} \text { or ANOVA } \\
F \text { test }\end{array}$ & $\begin{array}{l}\text { Total } \\
(n=1211)\end{array}$ \\
\hline Percentage of overall sample & 11.7 & 23.5 & 13.5 & 25.4 & 25.9 & & 100.00 \\
\hline \multicolumn{8}{|l|}{ Gender (\%) } \\
\hline Female & 46.48 & 59.86 & 48.47 & 59.28 & 52.23 & 0.0120 & 54.63 \\
\hline $\begin{array}{l}\text { Age } \\
\text { Mean (SD) }\end{array}$ & $45.6(15.7)$ & $49.4(14.4)$ & $40.2(13.5)$ & $46.7(13.3)$ & $55.1(15.0)$ & $<0.0001$ & $48.49(15.08)$ \\
\hline \multicolumn{8}{|l|}{ Education (\%) } \\
\hline Less than high school & 3.52 & 11.15 & 7.36 & 31.35 & 3.22 & $<0.0001$ & 12.78 \\
\hline High school & 13.38 & 32.73 & 18.40 & 24.75 & 19.29 & & 22.97 \\
\hline $\begin{array}{l}\text { Some university or completed } \\
\text { college }\end{array}$ & 28.17 & 17.63 & 30.06 & 17.16 & 38.26 & & 25.81 \\
\hline Completed undergraduate degree & 34.51 & 30.58 & 25.15 & 17.49 & 21.86 & & 24.73 \\
\hline Graduate degree & 20.42 & 7.91 & 19.02 & 9.24 & 17.36 & & 13.70 \\
\hline \multicolumn{8}{|l|}{ Yearly household income† (\%) } \\
\hline$<\$ 10000-\$ 30000$ & 17.14 & 40.14 & 20.59 & 29.86 & 13.74 & $<0.0001$ & 23.88 \\
\hline$\$ 30001-\$ 50000$ & 31.43 & 22.54 & 13.73 & 27.08 & 20.17 & & 22.29 \\
\hline$\$ 50001-\$ 80000$ & 27.14 & 19.72 & 28.43 & 23.61 & 24.46 & & 24.17 \\
\hline$\$ 80001-\$ 100000$ & 14.29 & 11.27 & 13.73 & 6.25 & 15.88 & & 12.45 \\
\hline$>\$ 100000$ & 10.00 & 6.34 & 23.53 & 13.19 & 25.75 & & 17.22 \\
\hline \multicolumn{8}{|l|}{ Marital status (\%) } \\
\hline Married/cohabiting & 58.57 & 79.29 & 73.01 & 93.79 & 58.01 & $<0.0001$ & 74.19 \\
\hline \multicolumn{8}{|l|}{ Employment status (\%) } \\
\hline Full-time & 47.89 & 40.71 & 55.83 & 55.63 & 43.45 & 0.0006 & 48.08 \\
\hline \multicolumn{8}{|l|}{ Immigrant status (\%) } \\
\hline Born in Canada & 29.58 & 5.63 & 34.15 & 2.61 & 80.25 & $<0.0001$ & 30.88 \\
\hline Years living in Canada Mean (SD) & $24.97(13.4)$ & $16.91(10.6)$ & $24.30(12.5)$ & $20.79(12.1)$ & $41.26(17.0)$ & $<0.0001$ & $22.02(13.7)$ \\
\hline \multicolumn{8}{|c|}{ Health status (\%) } \\
\hline \multicolumn{8}{|l|}{ Presence of } \\
\hline Heart disease & 3.55 & 4.59 & 6.75 & 6.51 & 9.55 & NS & 6.54 \\
\hline Arthritis & 7.80 & 10.64 & 9.82 & 17.32 & 19.75 & 0.0004 & 14.26 \\
\hline $\begin{array}{l}\text { High blood pressure or } \\
\text { hypertension }\end{array}$ & 17.73 & 15.55 & 17.68 & 19.87 & 22.93 & NS & 19.11 \\
\hline Depression & 5.67 & 3.94 & 9.15 & 13.36 & 15.92 & $<0.0001$ & 10.37 \\
\hline Diabetes & 6.34 & 6.07 & 10.98 & 14.98 & 8.92 & 0.0027 & 9.78 \\
\hline Any other chronic condition & 16.20 & 15.05 & 17.90 & 15.03 & 33.12 & $<0.0001$ & 20.28 \\
\hline \multicolumn{8}{|l|}{ Number of chronic conditions } \\
\hline One chronic condition & 39.29 & 39.93 & 47.85 & 54.25 & 63.38 & $<0.0001$ & 50.71 \\
\hline Two or more chronic conditions & 15.00 & 11.55 & 17.28 & 21.50 & 29.62 & $<0.0001$ & 20.00 \\
\hline Three or more chronic conditions & 2.82 & 3.20 & 5.52 & 8.47 & 11.46 & 0.0003 & 6.96 \\
\hline
\end{tabular}

Continued 


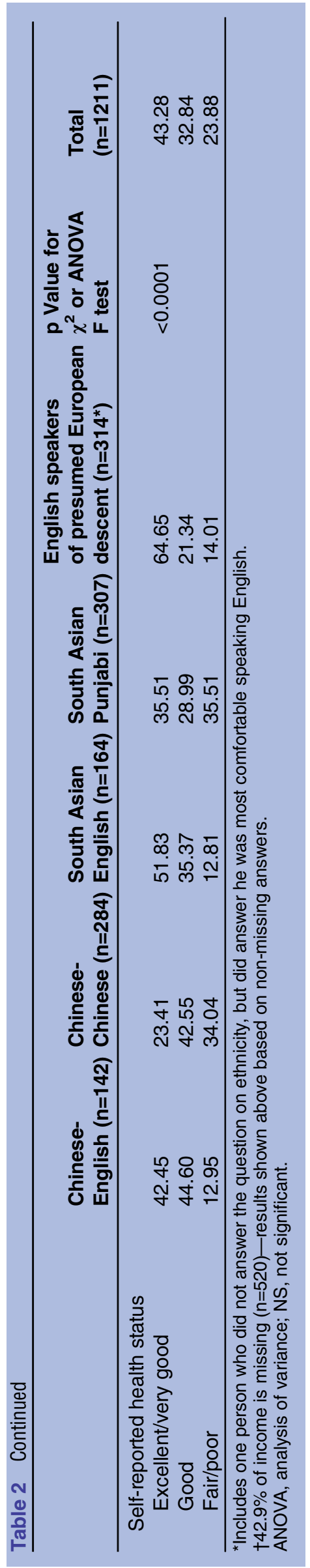

Obtaining care outside Canada

Table 3 shows results for patients' experiences in PHC. Among these groups, Chinese-speaking Chinese were more likely to obtain care outside Canada.

\section{Accessibility}

Compared with other ethnic-linguistic groups, the ESED group waited the shortest amount of time to see a provider at their usual place of care. Punjabi-speaking South Asians have the highest number of people who reported waiting over $60 \mathrm{~min}$ to see a provider at their usual place of care. Waiting over 1 month for needed healthcare was highest in the ESED group. Almost one in four English-speaking Chinese reported having to wait weeks to receive needed healthcare compared with other groups. Many (81\%) respondents could see their doctor within the next working day but the variation between groups ranged from $75 \%$ of English-speaking South Asians to $87 \%$ of Chinese-speaking Chinese.

\section{Utilisation and relationship continuity}

Compared with the ESED, Punjabi-speaking South Asians reported the highest number of times they visited their provider for physical and mental health issues. No differences were found in the relationship continuity among the ethnic and language groups.

\section{Interpersonal processes of care}

Among all the groups, Chinese-speaking Chinese reported significantly lower scores on all scales: unhurried communication, explanation of test results, patientcentered decision-making and interpersonal style, as compared with the ESED. Patient-centered decision-making was scored the lowest of the IPC scales by all participants.

\section{Quality and acceptability of care}

Compared with the ESED, Chinese-speaking Chinese had a significantly lower number of participants rate the quality of healthcare as 'excellent' or 'very good'. One in three Chinese-speaking Chinese and Punjabi-speaking South Asians reported the quality of PHC as fair/poor. South Asians, both English and Punjabi speakers, reported significantly lower acceptability of wait times for PHC.

The hierarchical linear regression results are shown in table 4.

Ethnic-linguistic group remained significantly related to confidence in PHC after controlling for sociodemographic characteristics and health status. Specifically, Chinese-speaking Chinese reported a lower confidence in PHC than did ESED. However, when participants' PHC experiences were entered into the regression model, the association between being Chinese-speaking Chinese and reports of lower confidence in PHC was attenuated. Patient experiences significantly associated with lower confidence in PHC included: if, in the past 12 months care was received outside Canada, they had to wait for months to see their regular doctor, or they 


\begin{tabular}{|c|c|c|c|c|c|c|c|}
\hline & $\begin{array}{l}\text { Chinese- } \\
\text { English }(n=142)\end{array}$ & $\begin{array}{l}\text { Chinese- } \\
\text { Chinese }(n=284)\end{array}$ & $\begin{array}{l}\text { South Asian } \\
\text { English } \\
(n=164)\end{array}$ & $\begin{array}{l}\text { South Asian } \\
\text { Punjabi }(n=307)\end{array}$ & $\begin{array}{l}\text { English Speakers of } \\
\text { presumed European } \\
\text { descent }\left(n=314^{*}\right)\end{array}$ & $\begin{array}{l}p \text { Value for } \\
\chi^{2} \text { or ANOVA } \\
F \text { test }\end{array}$ & $\begin{array}{l}\text { Total } \\
(n=1211)\end{array}$ \\
\hline Percentage of overall sample & 11.7 & 23.5 & 13.5 & 25.4 & 25.9 & & 100.00 \\
\hline \multicolumn{8}{|c|}{ Experiences outside of Canada (in past 12 months) } \\
\hline $\begin{array}{l}\text { Percentage who received healthcare outside } \\
\text { Canada }\end{array}$ & 10.00 & 19.50 & 6.13 & 8.55 & 5.10 & $<0.0001$ & 10.06 \\
\hline Post-hoc $p$ value & NS & $<0.0001$ & NS & NS & ref & & \\
\hline \multicolumn{8}{|l|}{ Experiences in Canada (in past 12 months) } \\
\hline \multicolumn{8}{|l|}{ Accessibility } \\
\hline Usual source of care (\%) & 92.25 & 92.58 & 93.25 & 91.83 & 93.61 & NS & 92.71 \\
\hline $\begin{array}{l}\text { Unmet healthcare needs Percentage who } \\
\text { needed healthcare but never received } \dagger\end{array}$ & 8.70 & 8.70 & 11.61 & 9.49 & 8.36 & NS & 9.19 \\
\hline \multicolumn{8}{|l|}{ Usual wait at regular place of care (min) } \\
\hline $0-10$ & 22.41 & 10.55 & 16.34 & 8.68 & 23.83 & & 15.59 \\
\hline$>10-20$ & 21.55 & 23.63 & 30.07 & 12.50 & 35.74 & & 24.46 \\
\hline$>20-30$ & 16.38 & 21.94 & 18.95 & 18.75 & 17.69 & $<0.0001$ & 18.95 \\
\hline$>30-60$ & 28.45 & 28.69 & 17.65 & 23.61 & 16.97 & & 22.69 \\
\hline$>60$ & 11.21 & 15.19 & 16.99 & 36.46 & 5.78 & & 18.30 \\
\hline Post-hoc $\neq p$ value & 0.0075 & $<0.0001$ & 0.0026 & $<0.0001$ & ref & & \\
\hline \multicolumn{8}{|l|}{ Wait for healthcare§ } \\
\hline $\begin{array}{l}\text { Percentage who needed to wait for } \\
\text { healthcare }\end{array}$ & 38.30 & 44.48 & 39.51 & 33.00 & 37.10 & NS & 38.26 \\
\hline \multicolumn{8}{|l|}{ Length of wait } \\
\hline$<1$ week & 58.82 & 62.30 & 65.00 & 76.04 & 41.74 & 0.0007 & 59.91 \\
\hline Weeks & 23.53 & 15.57 & 11.67 & 10.42 & 16.52 & & 15.09 \\
\hline Months & 17.65 & 19.67 & 18.33 & 12.50 & 29.13 & & 22.75 \\
\hline Never received & 0.00 & 2.46 & 5.00 & 1.04 & 2.61 & & 2.25 \\
\hline Post hoc $p$ value & NS & 0.0099 & NS & $<0.0001$ & ref & & \\
\hline \multicolumn{8}{|l|}{ Utilisation } \\
\hline \multicolumn{8}{|l|}{ Number of visits in past year for } \\
\hline $\begin{array}{l}\text { Physical health } \emptyset \\
\text { Mean (SD) }\end{array}$ & $2.90(3.27)$ & $2.96(3.86)$ & $3.97(4.17)$ & $5.85(6.65)$ & $3.99(4.96)$ & $<0.0001$ & $4.13(5.13)$ \\
\hline Post hoc $p$ value & NS & NS & NS & $<0.0001$ & ref & & \\
\hline Mental health** & $0.48(2.64)$ & $0.24(1.11)$ & $0.63(2.08)$ & $1.14(3.40)$ & $0.44(1.39)$ & 0.0001 & $0.61(2.30)$ \\
\hline \multicolumn{8}{|l|}{ Mean (SD) } \\
\hline Post hoc $p$ value & NS & NS & NS & 0.0012 & ref & & \\
\hline \multicolumn{8}{|c|}{ Relationship continuity } \\
\hline \multicolumn{8}{|c|}{ Length of time seeing same doctor or going to the same place (years) } \\
\hline$<1$ & 5.71 & 4.01 & 4.29 & 6.56 & 7.77 & NS & 5.88 \\
\hline $1-<3$ & 15.71 & 8.39 & 8.59 & 10.49 & 9.71 & & 10.16 \\
\hline $3-5$ & 15.00 & 19.71 & 20.25 & 18.03 & 15.53 & & 17.72 \\
\hline 6 or more & 63.57 & 67.88 & 66.87 & 64.92 & 66.99 & & 66.25 \\
\hline
\end{tabular}




\begin{tabular}{|c|c|c|c|c|c|c|c|}
\hline & $\begin{array}{l}\text { Chinese- } \\
\text { English }(n=142)\end{array}$ & $\begin{array}{l}\text { Chinese- } \\
\text { Chinese }(n=284)\end{array}$ & $\begin{array}{l}\text { South Asian } \\
\text { English } \\
(\mathrm{n}=164)\end{array}$ & $\begin{array}{l}\text { South Asian } \\
\text { Punjabi }(n=307)\end{array}$ & $\begin{array}{l}\text { English Speakers of } \\
\text { presumed European } \\
\text { descent }\left(n=314^{*}\right)\end{array}$ & $\begin{array}{l}p \text { Value for } \\
\chi^{2} \text { or ANOVA } \\
F \text { test }\end{array}$ & $\begin{array}{l}\text { Total } \\
(\mathrm{n}=1211)\end{array}$ \\
\hline \multicolumn{8}{|c|}{ Interpersonal communication (range 1-5; higher score is better) } \\
\hline Unhurried communication†† & $4.56(0.71)$ & $4.32(0.72)$ & $4.64(0.69)$ & $4.65(0.64)$ & $4.72(0.59)$ & $<0.0001$ & $4.58(0.68)$ \\
\hline \multicolumn{8}{|l|}{ Mean (SD) } \\
\hline Post hoc $p$ value & NS & $<0.0001$ & NS & NS & ref & & \\
\hline $\begin{array}{l}\text { Explained test results } \ddagger \\
\text { Mean (SD) }\end{array}$ & $4.11(1.17)$ & $3.64(1.18)$ & $4.25(1.18)$ & $4.00(1.37)$ & $4.48(0.99)$ & $<0.0001$ & $4.08(1.23)$ \\
\hline Post hoc $p$ value & NS & $<0.0001$ & NS & $<0.0001$ & ref & & \\
\hline $\begin{array}{l}\text { Patient-centered decision-making§§ } \\
\text { Mean (SD) }\end{array}$ & $3.40(1.35)$ & $3.06(1.23)$ & $3.09(1.32)$ & $3.31(1.32)$ & $3.63(1.38)$ & 0.0017 & $3.32(1.33)$ \\
\hline Post hoc $p$ value & NS & 0.0008 & 0.0065 & NS & ref & & \\
\hline $\begin{array}{l}\text { Interpersonal style, compassionate and } \\
\text { respectfulq1 } \\
\text { Mean (SD) }\end{array}$ & $4.35(0.86)$ & $3.84(0.92)$ & $4.53(0.77)$ & $4.44(0.96)$ & $4.46(0.84)$ & $<0.0001$ & $4.31(0.92)$ \\
\hline Post hoc $p$ value & NS & $<0.0001$ & NS & NS & ref & & \\
\hline \multicolumn{8}{|l|}{ Quality and acceptability } \\
\hline \multicolumn{8}{|c|}{ Overall rating of quality of healthcare received ${ }^{* * *}$} \\
\hline Excellent/very good & 52.94 & 16.81 & 49.35 & 36.68 & 69.54 & $<0.0001$ & 44.55 \\
\hline Good & 37.82 & 53.45 & 36.84 & 29.41 & 21.15 & & 34.45 \\
\hline Fair/poor & 9.24 & 29.74 & 13.81 & 33.91 & 9.32 & & 21.01 \\
\hline Post hoc $p$ value & 0.0031 & $<0.0001$ & $<0.0001$ & $<0.0001$ & ref & & \\
\hline $\begin{array}{l}\text { Acceptability scale††† (range 1-4; higher } \\
\text { score is better) }\end{array}$ & $3.63(0.73)$ & $3.33(0.91)$ & $3.16(1.00)$ & $2.87(1.11)$ & $3.58(0.80)$ & $<0.0001$ & 3.26 \\
\hline Post hoc $p$ value & NS & NS & 0.0002 & $<0.0001$ & ref & & \\
\hline 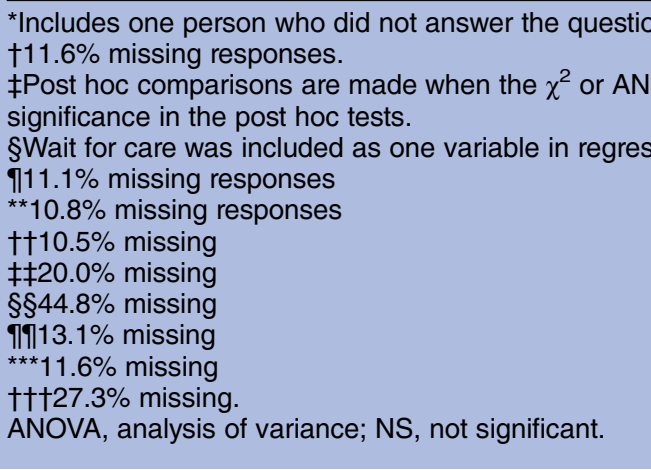 & $\begin{array}{l}\text { on ethnicity, but did } \\
\text { sVA F test are signific } \\
\text { sion models. }\end{array}$ & $\begin{array}{l}\text { d answer he was mos } \\
\text { cant }(p<0.05) . \text { The re }\end{array}$ & $\begin{array}{l}\text { st comfortable spe } \\
\text { eference category }\end{array}$ & $\begin{array}{l}\text { aking English. } \\
\text { is the Caucasian-E }\end{array}$ & English group. $p$ Value mus & st be less than & 1 for \\
\hline
\end{tabular}




\begin{tabular}{|c|c|c|c|c|c|c|c|c|}
\hline \multirow[b]{3}{*}{ Variable } & \multirow{2}{*}{\multicolumn{2}{|c|}{$\begin{array}{l}\text { Step } 1 \\
\text { Ethnic/language and } \\
\text { sociodemographic } \\
\text { variables } \\
(n=1181)\end{array}$}} & \multicolumn{2}{|l|}{ Step 2} & \multirow{2}{*}{\multicolumn{2}{|c|}{$\begin{array}{l}\text { Step } 3 \\
\text { Includes PHC } \\
\text { experiences outside } \\
\text { Canada } \\
(n=1152)\end{array}$}} & \multirow{2}{*}{\multicolumn{2}{|c|}{$\begin{array}{l}\text { Step } 4 \\
\text { Includes patient } \\
\text { experiences inside } \\
\text { Canada } \\
(n=673)\end{array}$}} \\
\hline & & & \multicolumn{2}{|c|}{$\begin{array}{l}\text { Includes health status } \\
(n=1165)\end{array}$} & & & & \\
\hline & Coefficient & p Value & Coefficient & p Value & Coefficient & p Value & Coefficient & p Value \\
\hline Ethnicity/language & & 0.0000 & & 0.000 & & 0.0003 & & NS \\
\hline Chinese-English & -0.40 & * & -0.13 & & -0.01 & & 0.07 & \\
\hline Chinese-Chinese & -1.37 & 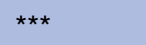 & -1.06 & $\star * \star$ & -0.74 & ** & -0.40 & \\
\hline South Asian-English & -0.47 & * & -0.11 & & -0.09 & & -0.25 & \\
\hline South Asian—Punjabi & -0.56 & *** & -0.29 & & -0.09 & & 0.12 & \\
\hline Caucasian_English & ref & & & & ref & & ref & \\
\hline Sociodemographic Characteristics & & & Not shown & & & & & \\
\hline $\begin{array}{l}\text { Gender; age; education; yearly household income; marital status } \\
\text { employment status; immigrant status } \dagger\end{array}$ & & & & & & & & \\
\hline Health status & & & Not shown & & & & & \\
\hline $\begin{array}{l}\text { Presence of heart disease, arthritis, high blood pressure or } \\
\text { hypertension, depression or diabetes; presence of two or more } \\
\text { chronic conditions; self-reported health status }\end{array}$ & & & & & & & & \\
\hline PHC experiences outside Canada & & & & & & & & \\
\hline Received healthcare outside Canada in the past 12 months & & & & & & 0.000 & & 0.035 \\
\hline No & & & & & ref & & ref & \\
\hline Yes & & & & & -0.81 & & -0.54 & \\
\hline PHC experiences inside Canada & & & & & & & & \\
\hline Accessibility & & & & & & & & \\
\hline Usual source of care & & & & & & & & NS \\
\hline No & & & & & & & 0.24 & \\
\hline Yes & & & & & & & ref & \\
\hline Unmet healthcare need $\neq$ & & & & & & & & NS \\
\hline No & & & & & & & ref & \\
\hline Yes & & & & & & & -0.04 & \\
\hline Usual wait at regular place of care (min) & & & & & & & & NS \\
\hline $0-10$ & & & & & & & ref & \\
\hline $10-20$ & & & & & & & 0.02 & \\
\hline $20-30$ & & & & & & & 0.01 & \\
\hline $30-60$ & & & & & & & 0.15 & \\
\hline More than 60 & & & & & & & -0.21 & \\
\hline Wait for healthcare & & & & & & & & \\
\hline Length of wait & & & & & & & & 0.044 \\
\hline Did not need to wait & & & & & & & ref & \\
\hline$<1$ week & & & & & & & 0.18 & \\
\hline Weeks & & & & & & & -0.15 & \\
\hline
\end{tabular}




\begin{tabular}{|c|c|c|c|c|c|c|c|c|}
\hline \multirow[b]{3}{*}{ Variable } & \multirow{2}{*}{\multicolumn{2}{|c|}{$\begin{array}{l}\text { Step } 1 \\
\text { Ethnic/language and } \\
\text { sociodemographic } \\
\text { variables } \\
(\mathrm{n}=1181)\end{array}$}} & \multicolumn{2}{|l|}{ Step 2} & \multirow{2}{*}{\multicolumn{2}{|c|}{$\begin{array}{l}\text { Step } 3 \\
\text { Includes PHC } \\
\text { experiences outside } \\
\text { Canada } \\
(n=1152)\end{array}$}} & \multirow{2}{*}{\multicolumn{2}{|c|}{$\begin{array}{l}\text { Step } 4 \\
\text { Includes patient } \\
\text { experiences inside } \\
\text { Canada } \\
(n=673)\end{array}$}} \\
\hline & & & \multicolumn{2}{|c|}{$\begin{array}{l}\text { Includes health status } \\
(n=1165)\end{array}$} & & & & \\
\hline & Coefficient & p Value & Coefficient & p Value & Coefficient & p Value & Coefficient & p Value \\
\hline Months & & & & & & & -0.58 & * \\
\hline Never received & & & & & & & -1.09 & \\
\hline \multicolumn{9}{|l|}{ Utilisation } \\
\hline \multicolumn{9}{|l|}{ Number of visits to doctor in past year for } \\
\hline Physical healthๆ & & & & & & & 0.0168 & NS \\
\hline Mental health $\dagger \dagger$ & & & & & & & -0.0011 & NS \\
\hline \multicolumn{9}{|l|}{ Relationship continuity of care } \\
\hline Length of time seeing same doctor or going to the same place ( & (ears) & & & & & & & NS \\
\hline$<1$ & & & & & & & -0.0161 & \\
\hline $1-<3$ & & & & & & & -0.4222 & \\
\hline $3-5$ & & & & & & & -0.3478 & \\
\hline 6 or more & & & & & & & ref & \\
\hline \multicolumn{9}{|l|}{ Interpersonal communication } \\
\hline Unhurried communicationףq & & & & & & & 0.06 & NS \\
\hline Explained test results $+\dagger$ & & & & & & & -0.08 & NS \\
\hline Interpersonal style, compassionate and respectfulłłł & & & & & & & 0.32 & 0.001 \\
\hline \multicolumn{9}{|l|}{ Quality and acceptability } \\
\hline \multicolumn{9}{|l|}{ Overall rating of quality of healthcare received in past 12 months $\S \S \S$} \\
\hline Excellent/very good & & & & & & & ref & 0.0000 \\
\hline Good & & & & & & & -0.89 & 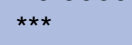 \\
\hline Fair/poor & & & & & & & -2.07 & 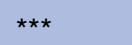 \\
\hline $\begin{array}{l}\text { Acceptability scale (scale score ranged from 1-4; higher score is } \\
\text { better) } 999 \text { ? }\end{array}$ & & & & & & & 0.26 & 0.001 \\
\hline Adjusted $R^{2}$ & 0.06 & & 0.09 & & 0.10 & & 0.30 & \\
\hline
\end{tabular}

$\dagger 42.9 \%$ of income is missing.

$\$ 11.6 \%$ missing.

\$11.1\% missing.

t† $10.8 \%$ missing

ๆๆๆ $10.5 \%$ missing.

†† $20.0 \%$ missing

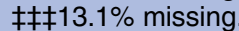

\$\$ $11.6 \%$ missing.

१โๆๆ $27.3 \%$ missing sufficient data to form acceptability scale.

PHC, primary healthcare. 


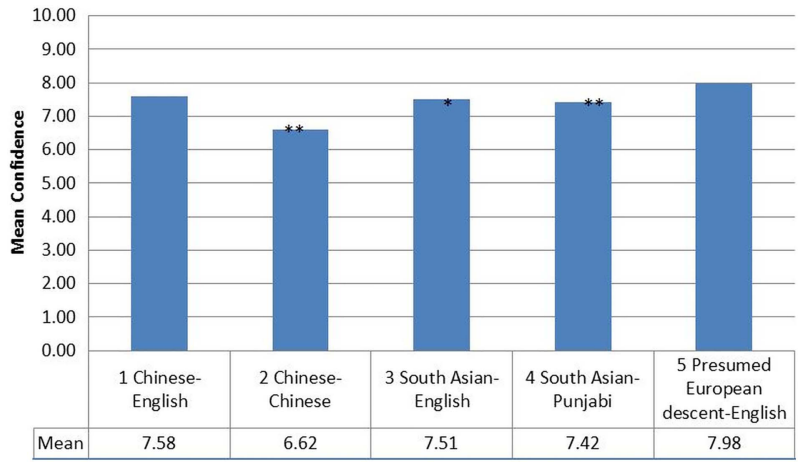

Figure 1 Confidence in primary healthcare.

rated the quality of healthcare received as good or fair/ poor. Higher reports of confidence in PHC was associated with participants' experiences in: perceiving their doctor was concerned about their feelings, that their doctor was respectful or if they found wait times for routine and urgent care acceptable. The final regression model explained $30 \%$ of the variance with many patient experience variables significantly and positively related to confidence in PHC. These variables far outweighed the impact of ethnicity and language alone on levels of confidence.

\section{DISCUSSION}

The results of this study suggest that, uniformly, confidence in PHC is less than ideal. No one group in this study scored close to 10. Moreover, confidence in PHC differs by ethnicity and the ability to speak English. These results provide evidence of the heterogeneity among ethnic groups. Work completed in the UK reported that South Asian and Chinese who speak English as a second language score lower on primary care surveys. ${ }^{41}$ Future examination of health disparities should take into account ethnicity and language.

Most of the effect of ethnicity and language on confidence, however, was influenced by aspects of the care experience. Increased confidence in PHC was related to certain aspects of the care experience such as providers' interpersonal style and acceptability of wait times. Recent work from the UK suggests that interpersonal communication is a driver of overall satisfaction with primary care. ${ }^{42}$ Structural changes to PHC that enable more positive interactions between patients and their usual provider/place of care and decreased wait times for appointments can serve to increase patients' confidence in PHC. It is important to build patients' confidence in PHC in order to be responsive to people's needs and potentially avoid increased health system costs where less confident patients may seek second and third opinions and have unnecessary or duplicative tests.

By tracking patients' experiences and confidence over time, insights into the ongoing importance of healthcare concerns for Canadians could be provided. While work of this nature is now being led by the Robert Wood
Johnson Foundation, ${ }^{43}$ this study provides a broad range of experiences that could be tracked as indicators for better understanding and forecasting changes in the PHC system. This type of work could provide important information on the quality of PHC. Confidence in PHC could be an indicator of 'consumer expectations' in healthcare, similar to the type of information gathered through the Index of Consumer Expectations, which is an official component of the US Department of Commerce's Index of Leading Economic Indicators. ${ }^{43}$

The results should be interpreted in light of this study's limitations. These were cross-sectional data collected in one Canadian province. Therefore, generalisability to other settings may be limited. Not all variables, such as the physician's ethnicity or preferred language, which are known to influence patient's confidence, were measured in this study. Having this variable available could have resulted in more of the variance of the regression model being explained. However, having the survey available in three different languages enabled us to collect data from a sample rarely included in self-report surveys. Only associations between patients' experiences and confidence in PHC can be inferred. While patients' experiences and their ratings of confidence in PHC can fluctuate over time, recent evidence from the US suggests that even despite an eventful year of health reform in 2010 , trends in patients' confidence remained stable. ${ }^{43}$ We can also draw on work from public opinion polls which suggest that for the most part, people do not have preformed, crystallised attitudes on public issues. ${ }^{44} 45$ Asking a question about confidence in a survey is a snapshot of an attitude that is never permanently crystallised but likely has some stability over time. Finally, this was a telephone survey which will not have reached those who do not have a telephone. Although the response rate for the ESED group was low, the response rates of the other groups were higher than a similar RDD survey completed in BC. ${ }^{45}$

Despite these limitations, patient experiences in $\mathrm{PHC}$ are associated with a person's confidence in the $\mathrm{PHC}$ system. Confidence in PHC is generally low, especially those who are Chinese-speaking Chinese. One reason for this group's low reported confidence in PHC could be based on their experience using the healthcare system in China. Despite major PHC reforms occurring in China, in urban areas, out-of-pocket payment for and receipt of PHC services from 'specialists' located in hospitals is still the norm. In addition, Chinese-speaking Chinese may believe that paying for services means care will be provided to certain standards. ${ }^{46}$ Even though Chinese-speaking Chinese in this sample had lived in BC for over 10 years, their low confidence scores could be based on the belief that skills of community-based PHC providers are low; in China, this belief is true since $25 \%$ of general practice physicians and approximately $2 \%$ of nurses having bachelor's level training with few receiving any training in general practice. ${ }^{46}$ Based on the results from our Chinese-speaking Chinese 
respondents, more work is needed to examine the relationship between obtaining healthcare services outside Canada and confidence in PHC in Canada.

In summary, overall confidence in $\mathrm{PHC}$ can be improved. Experiences of care in PHC, regardless of ethnicity or language spoken, can influence people's confidence in PHC. These findings have important implications for policy and decision makers. In countries with people who have diverse ethnic and language backgrounds, having positive PHC experiences is important. Work completed in the UK by Croker et at ${ }^{44}$ also provides evidence that, in particular, interpersonal aspects of a visit are strongly associated with reported confidence and trust in the doctor. Poor experiences of care, particularly for those who are not English speakers, could have a stronger overall impact on confidence, which could lead to delays in obtaining necessary services and possibly using more acute levels of care. This study provides a snapshot of how people who speak English, Chinese and Punjabi living in BC experience $\mathrm{PHC}$ and their confidence in the PHC system.

\section{Author affiliations \\ ${ }^{1}$ University of British Columbia (UBC) School of Nursing, Vancouver, British Columbia, Canada \\ ${ }^{2}$ UBC Centre for Health Services and Policy Research, Vancouver, British Columbia, Canada \\ ${ }^{3}$ UBC Department of Family Medicine, Vancouver, British Columbia, Canada ${ }^{4}$ UBC School of Population and Public Health, Vancouver, British Columbia, Canada \\ ${ }^{5}$ UBC Department of Political Science, Vancouver, British Columbia, Canada ${ }^{6}$ The Ottawa Hospital, Department of Quality and Patient Experience, Ottawa, Ontario, Canada \\ ${ }^{7}$ Department of Family Medicine, McGill University, Montreal, Quebec, Canada \\ ${ }^{8}$ Bureau of Health Information, Sydney, New South Wales, Australia \\ ${ }^{9}$ Centre for Primary Health Care and Equity, University of New South Wales, \\ Sydney, New South Wales, Australia}

Acknowledgements The authors would like to thank their research assistants and the men and women who participated in this study. The authors also especially acknowledge the support of Weihong Chen, Anureet Brar, Albert Wu, Sitaram Saroa and Emily Marshall in facilitating collection of data. They also thank Sandra Peterson and Leena Wu in their assistance with some of the data analysis and formatting, respectively.

Contributors STW oversaw all parts of the project, including conceptualisation, data collection and analysis and writing of the manuscript. $\mathrm{CB}$ and FC conceptualised and interpreted the analysis. RB conducted analysis of the data. JLH and J-FL helped to conceptualise the overall study, interpreted the analysis and aided in writing the manuscript. All authors contributed to the final version of the manuscript.

Funding This study was funded by a grant from the Canadian Institutes for Health Research grant number (166088).

Competing interests STW was supported by a scholar award from the Michael Smith Foundation for Health Research (Cl-SCH-051 (04-1)) and a new investigator award from the Canadian Institutes for Health Research. JLH was supported by the Canadian Institutes for Health Research and the Université de Sherbrooke as a Canada Research Chair. J-FL had a Fonds de la recherche en santé du Québec clinical scientist award.

Ethics approval The University of BC's Behavioral Ethics Board approved all procedures.

Provenance and peer review Not commissioned; externally peer reviewed.
Data sharing statement Deidentified data are available for use. Permission must be sought from STW (Sabrina.wong@nursing.ubc.ca)

Open Access This is an Open Access article distributed in accordance with the Creative Commons Attribution Non Commercial (CC BY-NC 3.0) license, which permits others to distribute, remix, adapt, build upon this work noncommercially, and license their derivative works on different terms, provided the original work is properly cited and the use is non-commercial. See: http:// creativecommons.org/licenses/by-nc/3.0/

\section{REFERENCES}

1. Armstrong K, Rose A, Peters N, et al. Distrust of the health care system and self-reported health in the United States. J Gen Intern Med 2006;21:292-7.

2. Gilson L. Trust and the development of health care as a social institution. Soc Sci Med 2003:56:1453-68.

3. Hall MA, Camacho F, Lawlor JS, et al. Measuring trust in medica researchers. Med Care 2006;44:1048-53.

4. Piette JD, Heisler M, Krein S, et al. The role of patient-physician trust in moderating medication nonadherence due to cost pressures. Arch Intern Med 2005;165:1749-55.

5. Thom DH, Hall MA, Pawlson LG. Measuring patients' trust in physicians when assessing quality of care. Health Aff (Millwood) 2004;23:124-32.

6. Gilson L. Trust in health care: theoretical perspectives and research needs. J Health Organ Manag 2006;20:359-75.

7. Hall MA, Dugan E, Zheng B, et al. Trust in physicians and medical institutions: what is it, can it be measured, and does it matter? Milbank Q 2001;79:613-39.

8. Hall JA, Roter DL. Do patients talk differently to male and female physicians? A meta-analytic review. Patient Educ Couns 2002;48:217-24.

9. Mechanic D. Changing medical organization and the erosion of trust. Milbank Q 1996;74:171-89.

10. O'Malley AS, Sheppard VB, Schwartz M, et al. The role of trust in use of preventive services among low-income African-American women. Prev Med 2004;38:777-85.

11. Safran DG, Kosinski M, Tarlov AR, et al. The primary care assessment survey: tests of data quality and measurement performance. Med Care 1998;36:728-39.

12. Thompson HS, Valdimarsdottir HB, Winkel G, et al. The group-based Medical Mistrust Scale: psychometric properties and association with breast cancer screening. Prev Med 2004;38:209-18.

13. Thom $\mathrm{DH}$, Ribisl KM, Stewart $\mathrm{AL}$, et al. Further validation and reliability testing of the Trust in Physician Scale. Med Care 1999;37:510-17.

14. Smedley BD, Stith AY, Nelson AR. Unequal treatment: Confronting racial and ethnic disparities in health care. Washington, DC: Nationa Academy Press, 2002. print.

15. Halbert $\mathrm{CH}$, Armstrong $\mathrm{K}$, Gandy $\mathrm{OH}$, et al. Racial differences in trust in health care providers. Arch Intern Med2006;166:896-901.

16. Boulware LE, Cooper LA, Ratner LE, et al. Race and trust in the health care system. Public Health Rep 1974;118:358-65.

17. LaVeist TA, Nickerson KJ, Bowie JV. Attitudes about racism, medica mistrust, and satisfaction with care among African American and White cardiac patients. Med Care Res Rev 2000;57:146-61. http:// www.ncbi.nlm.nih.gov/htbin-post/Entrez/query?db=m\&form=6\&dopt= r\&uid=11092161

18. Armstrong K, McMurphy S, Dean LT, et al. Differences in the patterns of health care system distrust between blacks and whites. $J$ Gen Intern Med 2008;23:827-33.

19. Doescher MP, Saver BG, Franks $P$, et al. Racial and ethnic disparities in perceptions of physician style and trust. Arch Fam Med 2000;9:1156-63. http://www.ncbi.nlm.nih.gov/htbin-post/Entrez/ query $? \mathrm{db}=\mathrm{m} \&$ form $=6$ \&dopt $=\mathrm{r} \&$ uid $=11115223$

20. Tarrant C, Stokes T, Baker R. Factors associated with patients' trust in their general practitioner: a cross-sectional survey. Br J Gen Pract 2003;53:798-800. http://www.pubmedcentral.nih.gov/articlerender. fcgi?artid=1314714\&tool=pmcentrez\&rendertype=abstract (accessed 3 Jul 2013).

21. Johnson RL, Roter D, Powe NR, et al. Patient race/ethnicity and quality of patient-physician communication during medical visits. $A m$ J Public Health 2004;94:2084-90.

22. Saha S, Taggert S, Komaromy K, et al. Do patients choose physicians of their own race? Health Aff (Millwood) 2000;19:76-83.

23. Haggerty J, Burge F, Gass D, et al. Operational definitions of attributes of primary health care to be evaluated: consensus among Canadian experts. Ann Fam Med 2007;5:336-44.

24. Employee Research Benefit Institution. Employee Benefit Research Institute. 2013. http://www.ebri.org (accessed 1 Nov 2013). 
25. Mathew Greenwald \& Associates. Mathew Greenwald \& Associates. 2007. http://www.greenwaldresearch.com/aboutus/ multisponsoropps\#HCS (accessed 1 Nov 2013).

26. Herdman M, Fox-Rushby J, Badia X. A model of equivalence in the cultural adaptation of HRQoL instruments: The universalist approach. Qual Life Res 1998;7:323-35.

27. Patrick DL, Wild DJ, Johnson ES, et al. Cross-cultural validation of quality of life measures. In: Orley J, Kuyken W. eds Quality of life assessment: international perspectives. Berlin, Heidelberg: Springer Berlin Heidelberg, 1994:19-32.

28. Hui $\mathrm{CH}$, Triandis HC. Measurement in cross-cultural psychology: a review and comparison of strategies. J Cross Cult Psychol 1985;16:65-83.

29. Guillemin F, Bombardier C, Beaton D. Cross-cultural adaptation of health-related quality of life measures: Literature review and proposed guidelines. J Clin Epidemiol 1993;46:1417-32.

30. Flaherty JA. Appropriate and inappropriate research methodologies for Hispanic mental health. In: Gaviria M, Arana JD. eds Health and behavior: research agenda for Hispanics. Chicago, IL: University of Illinois, 1987:177-86.

31. Flaherty JA, Gaviria M, Pathak D, et al. Developing instruments for cross-cultural psychiatric research. J Nerv Ment Disord 1988;176:257-63.

32. Harris-Kojetin LD, Fowler FJ, Brown JA, et al. The use of cognitive testing to develop and evaluate CAHPS $^{\mathrm{TM}} 1.0$ core survey items. Med Care 1999;37:MS10-21.

33. Sudman S, Warnecke R, Johnson T, et al. Cognitive aspects of reporting cancer prevention examinations and tests. Maryland, USA U.S. Department of Health and Human Services, 1994. http://stacks. cdc.gov/view/cdc/6223/

34. Sudman S, Bradburn NM, Schwarz N. Thinking about answers: the application of cognitive processes to survey methodology. San Francisco, CA: Jossey-Bass Inc, 1996.

35. ASDE. ASDE Survey Sampler. 2003;2006. http://www. surveysampler.com/en/company/team.html
36. Khan S, Mclntosh C, Sanmartin C, et al. Primary health care teams and their impact on processes and outcomes of care. Ottawa, ON, 2008. http://epe.lac-bac.gc.ca/100/200/301/statcan/health_research_ working_papers-e/02/82-622-XIE2008002.pdf

37. Health Council of Canada. Fixing the foundation: An update on primary health care and home care renewal in Canada. Toronto, ON Health Council of Canada, 2008. http://www.healthcouncilcanada.ca/ docs/rpts/2008/.../HCC_PHC_Main_web_E.pdf

38. Stewart AL, Napoles-Springer AM, Gregorich SE, et al. Interpersonal Processes of Care Survey: patient-reported measures for diverse groups. Health Serv Res 2007;43:1235-56.

39. Nunnally JC. Psychometric theory. 2nd edn. New York, NY: McGraw-Hill Company, 1978.

40. American Association for Public Opinion Research. AAPOR: American Association for Public Opinion Research. http://www. aapor.org/Home.htm (accessed 2 Jul 2013)

41. Paddison CAM, Abel GA, Roland MO, et al. Drivers of overall satisfaction with primary care: Evidence from the English General Practice Patient Survey. Heal Expect. Published Online First: 30 May 2013.

42. Lyratzopoulos G, Elliott M, Barbiere JM, et al. Understanding ethnic and other socio-demographic differences in patient experience of primary care: evidence from the English General Practice Patient Survey. BMJ Qual Saf 2012;21:21-9.

43. State Health Data Assistance Center. Robert Wood Johnson Foundation Health Care Public Perception Index. SHADAC/Robert Wood Johnson Found, 2011. http://www.rwjf.org/en/researchpublications/find-rwjf-research/2011/02/robert-wood-johnson-foundationhealth-care-public-perception-ind.html (accessed 2 Jul 2013).

44. Croker JE, Swancutt DR, Roberts MJ, et al. Factors affecting patients' trust and confidence in GPs: evidence from the English national GP patient survey. BMJ Open 2013;3:e002762.

45. Wong ST, Peterson S, Black C. Patient activation in primary healthcare: a comparison between healthier individuals and those with a chronic illness. Med Care 2011;49:469-79.

46. Bhattacharyya O, Delu Y, Wong ST, et al. Evolution of primary care in China 1997-2009. Health Policy 2011;100:174-80. 